\title{
Deinstitutionalised patients, homelessness and imprisonment: systematic review ${ }^{\dagger}$
}

Petr Winkler, Barbara Barrett, Paul McCrone, Ladislav Csémy, Miroslava Janoušková and Cyril Höschl

\section{Background}

Reports linking the deinstitutionalisation of psychiatric care with homelessness and imprisonment have been published widely.

\begin{abstract}
Aims
To identify cohort studies that followed up or traced back long-term psychiatric hospital residents who had been discharged as a consequence of deinstitutionalisation.

\section{Method}

A broad search strategy was used and 9435 titles and abstracts were screened, 416 full articles reviewed and 171 articles from cohort studies of deinstitutionalised patients were examined in detail.
\end{abstract}

\section{Results}

Twenty-three studies of unique populations assessed homelessness and imprisonment among patients discharged from long-term care. Homelessness and imprisonment occurred sporadically; in the majority of studies no single case of homelessness or imprisonment was reported.

\section{Conclusions}

Our results contradict the findings of ecological studies which indicated a strong correlation between the decreasing number of psychiatric beds and an increasing number of people with mental health problems who were homeless or in prison.

\section{Declaration of interest} None.

\section{Copyright and usage}

(c) The Royal College of Psychiatrists 2016.
In 1939 Penrose examined European statistics on prison and psychiatric hospital populations and introduced what is now known as the 'hydraulic hypothesis'. This hypothesis presents the idea that the number of prisons increases as the number of psychiatric beds decreases. ${ }^{1-4}$ The idea gained prominence in the era of deinstitutionalisation, ${ }^{3,5,6}$ and has been revisited following deinstitutionalisation in South America. ${ }^{78}$ Deinstitutionalisation emerged in the 1950s and 1960s in the USA and UK and was triggered by humanitarian, economical and societal factors. ${ }^{9-12}$ Subsequently this policy was pursued in Canada, ${ }^{13,14}$ western Europe,${ }^{15,16}$ northern Europe ${ }^{17-19}$ southern Europe, ${ }^{20,21}$ noncommunist central European countries, ${ }^{22}$ Australia, ${ }^{23,24}$ New Zealand, ${ }^{25}$ Jamaica, ${ }^{26,27}$ and in other parts of the world. In many countries it is still an ongoing process. ${ }^{22}$ However, in central and eastern Europe and in east and southeast Asia, mental healthcare still relies heavily on large psychiatric hospitals and therefore deinstitutionalisation is central to mental health reforms in these areas. $^{28,29}$

Since deinstitutionalisation began, arguments that psychiatric reforms have led to former patients entering prisons and becoming homeless have been prolifically published in the professional literature, ${ }^{5,30-33}$ as well as in newspapers. ${ }^{34}$ As a rule, these arguments have been based on either ecological studies or more often - personal observations or judgements. Ecological studies are observational studies that work with aggregated rather than individual data. Such studies resulted in contradictory findings. Priebe et al, Hodgins et al, Raphael \& Stoll and Kramp \& Gabrielsen, for example, came to the conclusion that where there were fewer psychiatric beds there were more criminal convictions of those with mental disorders. ${ }^{20,35-37}$ On the other hand, Wallace et al and Hartvig \& Kjelsberg, for instance, came to the opposite conclusion and did not attribute increased criminal convictions to deinstitutionalisation. ${ }^{33,38}$ No matter what

†See editorial, pp. 412-413, this issue. the findings, ecological studies face the risk of ecological fallacy, i.e. invalid inference on causal relationship from group data to individual level.

The limitations of ecological studies might be overcome by cohort studies. Some studies approached people who were homeless or in prison and then detected a history of psychiatric treatment at the individual level: see, for instance, Bassuk \& Lamb and Whitmer. ${ }^{39,40}$ The problem with such studies is an implicit assumption that these people, usually with new and acute disorders, would not end up homeless or in prison under the old system dominated by psychiatric hospitals. It is an assumption that the old system would somehow deal better with the new societal situation.

Maj, on behalf of the World Psychiatric Association and in concordance with the World Health Organization (WHO) and the European Commission, stated that deinstitutionalisation should be regarded as a priority worldwide. ${ }^{41-43}$ However, the question of homelessness and criminality among patients discharged from the institutions has not been resolved, ${ }^{44}$ and may become an obstacle to reform efforts. For instance, in the Czech Republic some psychiatrists and media outlets published messages predicting that mental health reform would drive people with psychosis into homelessness and imprisonment. ${ }^{45-49}$ This backlash phenomenon has been described during the early years of deinstitutionalisation in the USA and is referred to as antideinstitutionalisationism. ${ }^{10}$ Cohort studies of discharged patients might help to shed light on whether or not deinstitutionalisation has led to homelessness and criminality. These studies could either use a follow-up design, assessing participants at baseline and then repeatedly for a long period, or they could follow a trace-back design in which cases of patients discharged some time ago are re-examined. We aimed to identify such cohort studies and assess homelessness and imprisonment among those with severe mental disorders who were discharged from psychiatric hospitals as a consequence of deinstitutionalisation. A further aim was to assess suicidality among these former patients as it was suggested that a 
reduction in psychiatric beds might increase suicide rates. ${ }^{48,49}$ This review was conducted to bring new insights into the controversy; in other words, we hoped to replace rhetoric with evidence. This should inform decision makers, especially in countries where institutional mental healthcare predominates, and help them to pursue a good strategy for mental healthcare development. Deinstitutionalisation is the official WHO policy for Europe; however, if it leads to homelessness and criminality, the price to be paid may be perceived as too high by both policy makers and the public.

\section{Method}

A systematic literature review in compliance with the Preferred Reporting Items for Systematic Reviews and Meta-analyses (PRISMA) guidelines was conducted between July 2013 and February 2014. The study population was defined as people with severe mental disorders who had been resident in a psychiatric hospital for more than 1 year, whose main disability was not related to old age (dementia) or intellectual disabilities, and were 18-65 years old. If patients were older, the study could still be included if it was made clear that those with dementia were not eligible. People with dementia and those with intellectual disabilities were excluded because they do not represent typical populations of mental hospitals; rather, there are specialist institutions for both of these groups. The definition of length of stay was chosen in line with other studies that defined a long-term patient as someone treated in hospital for more than a year. ${ }^{50-53}$ However, some studies defined long-term patients as those with a duration of stay longer than 6 months, ${ }^{54,55}$ and yet other studies used minimum periods of up to 2 years. ${ }^{56}$

Intervention was defined as a discharge of patients from psychiatric hospitals that was driven by deinstitutionalisation, defined broadly as a policy of significant reduction in the number of psychiatric beds or total closure of hospitals. The simultaneous development and functioning of community care was not necessary for a study to be included in the final analysis, although this would have had probably influenced the outcomes of interest. Only patients discharged from general as opposed to secure psychiatric hospitals were included in our review. Comparison of different groups of patients was not considered to be relevant.

Outcomes were primarily defined as criminality and homelessness among discharged patients. Criminality was expressed as the number of people who ended up in prison at some point during the follow-up period and thus was concerned mainly with serious offences. Homelessness was identified through the number of people who were known to have become homeless or had used services for homelessness at some point during the follow-up period. The rate or number of suicides was also examined.

To meet inclusion criteria studies had to have a cohort design and either follow up or trace back the discharged patients. Studies based on data gathered from registers (unless they contained individual patients' data) were excluded. Individual case reports were excluded from the final analysis, as they would introduce systematic bias. Best efforts were made to obtain grey literature with possibly relevant data; no time restraints were applied, and studies published in English, German, French or Dutch were included in the analysis.

\section{Search strategy}

Scientific databases were searched in two phases. The pilot phase took place in July 2013, and PubMed/Medline was chosen for the initial search. Nineteen potentially eligible articles were identified: eight examined homelessness and criminality among deinstitutionalised patients, two of which were concerned with the TAPS study population. These 19 articles were analysed and relevant information extracted. Reference lists were searched for additional articles, as was the review published later that year by Kunitoh. ${ }^{54}$ The pilot demonstrated that a broad search strategy was necessary to identify all potentially eligible studies. For example, some studies did not refer to 'deinstitutionalisation' but rather to psychiatric or mental hospital closure, others used the term 'transinstitutionalisation' or 'reinstitutionalisation' in order to describe the process of how people ended up in other institutions, including prisons and institutions for homeless people. Some studies did not use any of these terms and spoke simply about patients discharged from psychiatric hospitals.

The second search phase took place in October, November and December 2013. The search strategy was developed, tested, adjusted and finally applied at PubMed/Medline (up to November 2013 week 2) and Web of Knowledge (including Web of Science from 1900 and Medline from 1950, both up to November 2013 week 2), and subsequently also adjusted for databases working on Ovid platform including PsycINFO, Health Management Information Consortium and Social Policy and Practice (all searched up to December 2013 week 2). A combination of truncated and asterisked words deinstitutionalisation, crime, homelessness, psychiatry, reinstitutionalisation, transinstitutionalisation, psychiatric hospital, mental hospital, discharge and closing was used to identify possibly relevant studies in peer-reviewed journals as well as grey literature (see online supplement DS1 for more details). The Cochrane Library was searched simply using 'deinstitutionali?ation' for title, abstracts and keywords; the last search was conducted in January 2014 week 5.

\section{Results}

The search strategy resulted in over 9416 unique and possibly relevant pieces of literature. Most relevant articles were identified by this strategy, although a few $(n=19)$ other potentially eligible articles were identified through references, authors and experts (Fig. 1).

\section{Included studies}

Twenty-three studies representing unique populations of deinstitutionalised patients from Albania, Australia, Austria, Canada, England, Wales, Finland, Ireland, Italy, Japan, Northern Ireland, Scotland and USA were identified and analysed (Table 1). The years of patient discharge ranged from 1970 (Australia) up to 2011 (Albania), ${ }^{57,58}$ which effectively means that the earliest period of deinstitutionalisation was not covered. The first studies conducted in the USA and the UK were of patients discharged between 1980 and 1986 (USA) and between 1982 and 1984 (UK). No eligible study from Latin America was found. The included studies are described in detail in online supplement DS2, and excluded studies in supplement DS3. The included studies differed in quality and ranged from local cohort studies with as few as 14 respondents, ${ }^{59}$ to studies conducted on a national scale with as many as 3307 respondents. ${ }^{60}$ The studies of highest quality were conducted by the TAPS team in England and by Honkonen et al in Finland. ${ }^{50,60}$ These were methodologically rigorous and included large cohorts of patients. However, there was a considerable loss to follow-up in the Finnish study. ${ }^{60}$ Both studies reported few adverse consequences and that patients were more satisfied in the community than in the hospital.

The percentage of women respondents ranged from $15 \%$ to $100 \%,{ }^{52,58}$ and the proportion of those with schizophrenia ranged from $48 \%$ to $100 \% .^{59-62}$ The mean age of discharged patients 


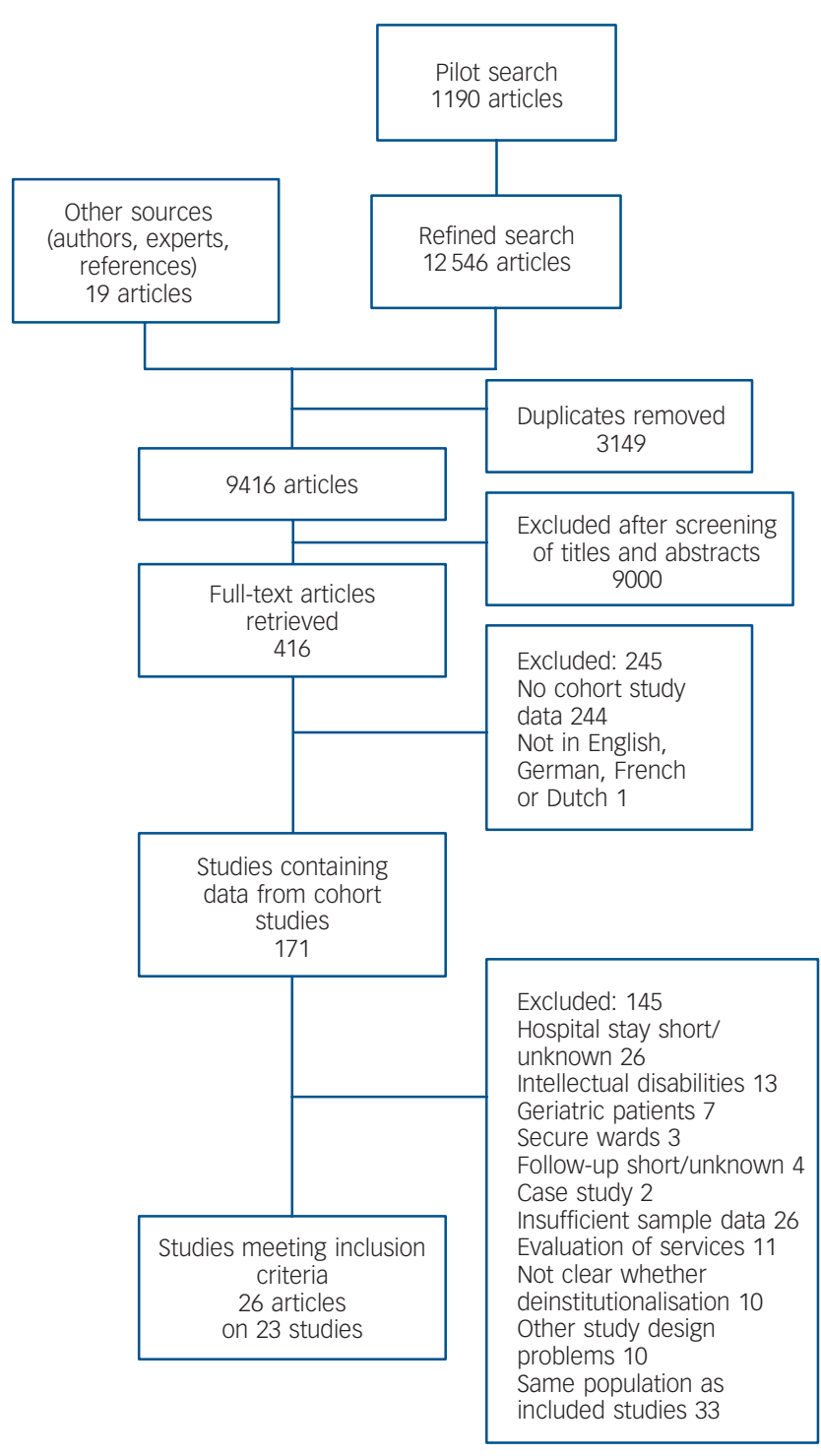

Fig. 1 PRISMA flowchart.

varied between 37.6 years and 67.3 years. ${ }^{63,64}$ All discharged patients had a lengthy stay in psychiatric hospital, ranging from 8 years to 37 years, ${ }^{65-67}$ and were followed up from 1 year to 14.1 years after discharge. ${ }^{68,69}$ The studies by Farragher et al, McInerney et al and Furlan et al had high rates of loss to follow-up (47\%, 33\% and 19\% respectively) due to high death rates. $52,67,69$ One study had a $22 \%$ loss to follow-up due to readmission of previously discharged patients. ${ }^{65}$ Rates of refusal to participate in the follow-up were highest in the studies by Honkonen et al and Leff ( $9 \%$ and 3\% respectively). ${ }^{50,60}$ Otherwise, refusals to follow-up were rare. The rate of untraced patients was under $1 \%$ in the majority of studies, but reached $5 \%$ in the study by Honkonen et al and $4 \%$ in the studies by Lesage et al and Haberfellner et al. ${ }^{9,60,61}$

Out of 23 studies, 15 reported no case of homelessness among discharged patients. Barbato et al reported 1 case out of 163 patients $(0.6 \%))^{71}$ Leff reported 7 cases out of 737 patients $(0.9 \%),{ }^{50}$ Mastroeni et al reported 1 case out of 97 patients $(1 \%),{ }^{72}$ Rothbard et al reported 6 cases out of 321 patients $(1.9 \%),{ }^{73}$ and Jones et al reported 1 case out of 50 patients (2\%). ${ }^{53}$ Honkonen et al, McGrew et al and Lesage et al reported $0-22(0-0.7 \%), 0-4(0-4.2 \%)$ and $0-7(0-2.3 \%)$ possible cases of homelessness out of 3307, 96 and 303 patients respectively. ${ }^{9,60,65}$ Problems with housing other than homelessness were identified in some studies (online supplement DS2).

The number of discharged patients who ended up in prison was recorded in 18 studies; of these, 11 reported that no patient was imprisoned. Donnelly et al found 1 out of 321 patients in prison $(0.3 \%),{ }^{74}$ Leff found 2 out of 737 patients in prison $(0.3 \%),{ }^{50}$ McInerney et al found 1 out of 87 patients in prison $(1.1 \%),{ }^{52}$ McGrew et al found 4 out of 303 patients in prison $(1.3 \%),{ }^{65}$ Barr \& Parker found 2 out of 140 patients in prison $(1.4 \%),{ }^{57}$ Okin et al reported that 1 out of 64 patients was imprisoned (1.6\%), ${ }^{63}$ and Thornicroft et al found 3 out of 73 discharged patients $(4.1 \%) .{ }^{64}$ Misdemeanours that had not led to imprisonment occurred occasionally.

Suicide rates were reported in 18 studies, and of these 11 indicated that no suicide occurred. The highest rates of suicide were reported by McInerney et al, who found that 3 out of 87 patients died by suicide $(3.4 \%)$ (S. J. McInerney, personal communication, 2014), Farragher et al who found that 4 out of 226 patients died by suicide (1.8\%) and Andrews et al who found that 3 out of 208 patients died by suicide $(1.4 \%) .{ }^{52,75,76}$

\section{Discussion}

Deinstitutionalisation has been criticised, mainly in the USA, where it was considered to have been poorly organised, resulting in lower levels of funding or budget cuts, and also to have been inconsistent with stated political declarations. ${ }^{39,77-88}$ This has been concisely described by Dumont \& Dumont, who stated that the original US plan, developed under the presidencies of John F. Kennedy and Lyndon Johnson, included an investment of $\$ 7$ billion and establishment of 2000 community mental health centres across the USA ${ }^{89}$ however, this plan was not realised as Johnson's successor, Richard Nixon, substantially restricted its funding. The appropriateness of the delivery of community care has also been criticised elsewhere, for example in Denmark and Canada. ${ }^{17,90}$

Ecological studies have been widely used to research the consequences of deinstitutionalisation, and often conclude that decreasing the number of beds in mental hospitals leads to more people with mental illness in prison or on the streets. Our review does not support this, and we think that these ecological studies might have been confounded. Rather than deinstitutionalisation, other societal factors such as rapid globalisation, increases in migration, growing individualism, less emphasis on traditional families, pressures on housing and the labour market, increased illegal drug use, growing unemployment, legal changes (e.g. those associated with the war on drugs), changes in mental healthcare funding and associated budget cuts could have all contributed to the rising number of people with mental health problems who end up in prison or homeless in the USA and in western Europe. Durham emphasised that the context of deinstitutionalisation in the USA was characterised by restrictive changes in Medicaid, social security and disability payment systems, and by the reduction in low-cost housing and other sociopolitical changes. ${ }^{88}$

Countries in Latin America have also undergone deep societal changes in the past 30 years. Although the overall burden of psychiatric and neurological disease has grown tremendously, investment in mental healthcare has remained low, and other societal challenges have emerged. ${ }^{91}$ Again, in this context, it might be not surprising that the study by Mundt et al, which analysed data related to deinstitutionalisation in Latin America, found an association between a decreasing number of mental health beds 


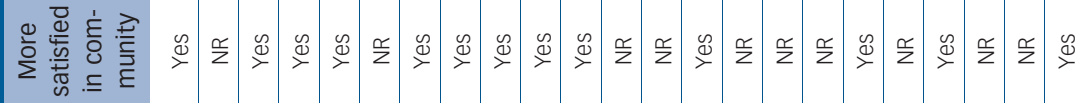

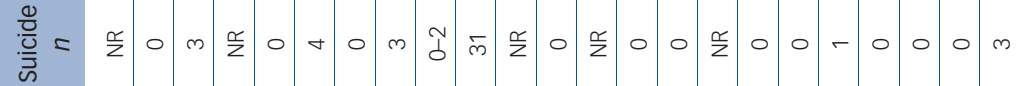

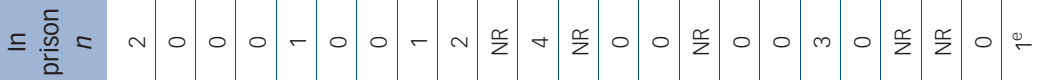

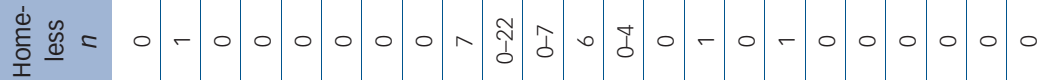

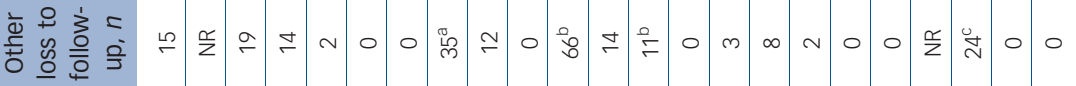

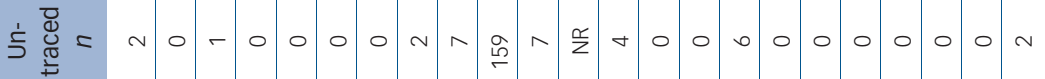

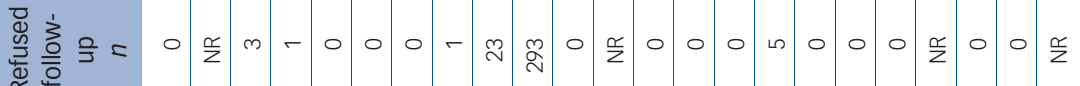

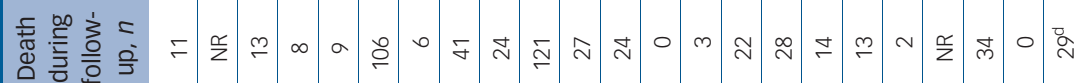

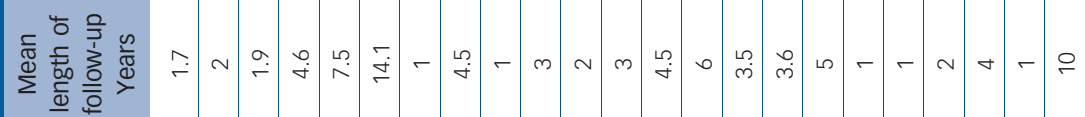

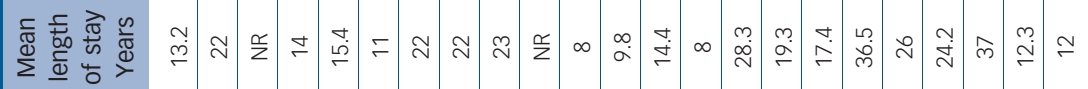

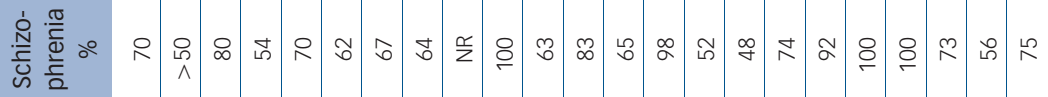

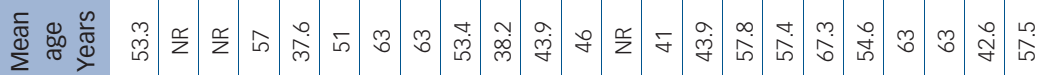

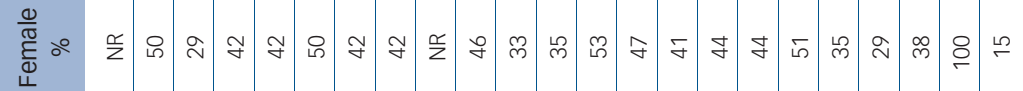

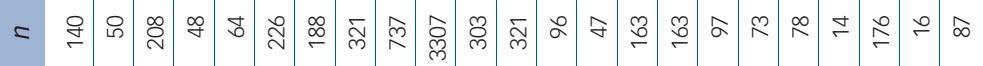

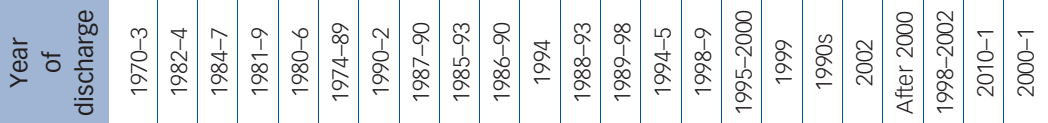

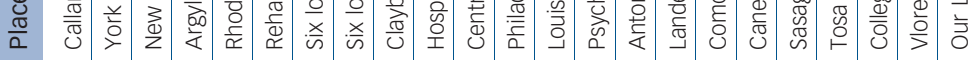

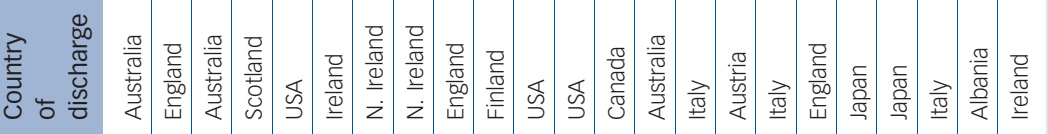

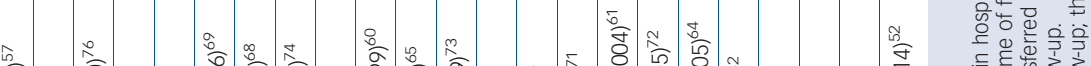

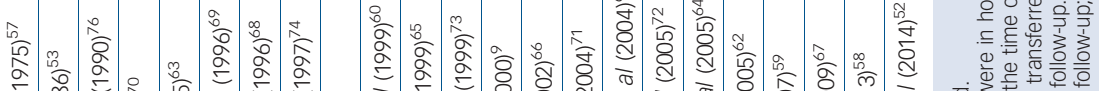

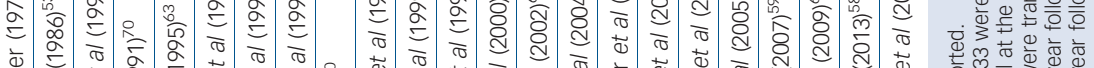

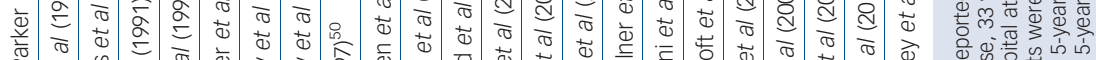

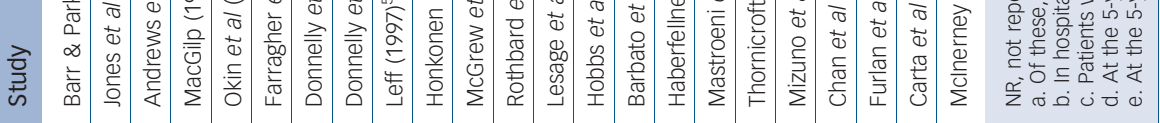


and an increasing number of prison places. ${ }^{8}$ The study's authors were, however, aware of its limitations, and indicated that an increase in the number of prison places cannot be solely explained by decreases in the number of hospital beds. They suggest that more evidence is required to determine the pathways leading people with mental health problems into prison. ${ }^{8}$

The evidence presented here comes from cohort studies of long-term psychiatric patients discharged into the community. These studies might be more helpful than ecological studies in determining direct causality between deinstitutionalisation and homelessness and criminality. ${ }^{92}$ Our review shows that such studies were conducted on different cohorts of patients and in a number of different countries. Analysis of these studies demonstrates that homelessness and criminality among discharged patients occurred sporadically, and suggests that even patients who were discharged after many years in hospital did well in the community. This is in line with the evidence presented by Kunitoh ${ }^{54}$ who conducted a systematic review and concluded that deinstitutionalisation was generally beneficial for the majority of discharged patients in terms of both social functioning and quality of life. It also supports findings made by Rothbard \& Kuno, who analysed four cases of deinstitutionalisation in Europe and suggested that discharging long-stay patients to the community might be easier than is usually assumed. ${ }^{93}$ Our study reveals little evidence of negative consequences of deinstitutionalisation globally.

\section{Limitations}

Patients from the studies analysed here are not representative of all deinstitutionalised patients. Untraced and unreported patients could have biased the results, although it would be far from appropriate to conclude that untraced patients were either in prison or homeless. Analyses of withdrawal, which were conducted in some studies (for example those by Honkonen et al and Gardos et al), ${ }^{60,94}$ showed that these patients did better at baseline, and therefore might have had improved health during the follow-up and as a consequence deliberately lost contact with mental health services. In addition, there might have been some unreported negative outcomes in primary studies, for instance those that occurred among patients who were already dead by the time of the follow-up. Differences in length of stay, age, gender distribution, place and means of discharge, availability of community services and year of discharge were detected in included studies and make direct comparisons more difficult. Furthermore, mean values might be unrepresentative because outliers could skew the distribution. This was probably the case for many studies analysed here, but this influenced only the sociodemographic profile of patients and not the outcomes of interest - homelessness, imprisonment, suicidality - as these have a binary form (yes or no). There were considerable differences in the follow-up periods, which ranged from 1 year to 25 years. Studies with longer follow-up are expected to have higher dropout rates and also a greater chance that some of the respondents would become homeless, commit a serious offence or die by suicide. Differences in the health status and history of psychiatric treatment of the population in the studies may be attributed to differences in diagnostic profiles. In some cases, for example in the study by Furlan et al, ${ }^{67}$ the mean age of patients was close to 65 years; thus, some might have had age-related disorders such as dementia, which could slightly bias the results. In many studies there were some patients with personality disorders and drug misuse, and it is not entirely clear whether these were the patients who eventually became homeless or were imprisoned.

A further limitation relates to the place of stay after discharge from hospital. Some of the patients were discharged to nursing homes, and it is questionable whether these can be considered to be proper community facilities. The same applies to the Sasagawa project. ${ }^{62}$ The Sasagawa hospital was converted into a facility with traditional living accommodation and it is arguable whether this represents 'regular' deinstitutionalisation. Additionally, the definition of homelessness was not addressed in the majority of studies. For instance, in the study by Rothbard et al, everyone who had ever been admitted to a homeless shelter was considered to be homeless, no matter how long this period had lasted. ${ }^{73}$ On the other hand, Double \& Wong found two former patients in a Sheffield hostel for homeless men, but did not record them as homeless. ${ }^{95}$ The problem of definition also applies to criminality. There are a number of ways to measure criminality, such as self-reports, police reports, number of trials and records from country-specific registers. Our review focused on serious offences only and reported the number of those who ended up in prison after being discharged from psychiatric hospitals. Less serious offences, as well as other relevant details from primary studies, are reported in online supplement DS2.

\section{New cohorts and short-term patients}

Despite its limitations, our review suggests that deinstitutionalisation has not resulted in substantial homelessness and imprisonment among discharged long-term patients. It may be, however, postulated that deinstitutionalisation has had a negative effect on new cohorts of patients without access to a psychiatric hospital. This hypothesis is difficult to test. A randomised controlled trial and 5-year follow-up of newly admitted patients with schizophrenia spectrum disorder in Denmark did not find evidence to justify hospital-based treatment, ${ }^{96}$ and a study by Wahlbeck suggested that deinstitutionalisation in Nordic countries, where appropriate community services were available, might have contributed to a reduction in the life expectancy gap between those with mental health problems and general population, ${ }^{97}$ but still it is difficult to entirely rule out the aforementioned hypothesis.

It may be also argued that recipients of long-term hospital care have stabilised disorders and are thus at a lower risk of unwanted outcomes than those in their first year of severe mental illness. This argument, however, is not against deinstitutionalisation. It stresses the need for availability of mental health services and mental health beds, but does not imply that these have to be located in large psychiatric institutions. On the contrary, Housing First and assertive community treatment are both communitybased services that have been shown to be effective in working with homeless people with mental health problems. $^{98-100}$ Although it might be more expensive to provide such comprehensive care in the community, this does not make it less cost-effective, and it is a human right to live independently and to be included in the community. ${ }^{101}$

\section{Implications}

The perfect methodological approach that would allow a clear conclusion on the association between deinstitutionalisation, homelessness and imprisonment is unclear. This systematic review, however, demonstrates that the number of former longstay patients who became homeless or imprisoned after discharge was not excessive, contrary to popular argument. The findings suggest that some of the ecological studies may have been confounded. Cohort studies that followed up or traced back people discharged from long-term psychiatric care show that these patients benefited from the transfer to the community and that serious behavioural problems such as homelessness, 
imprisonment or suicide did not occur frequently. However, this might have been different with patients with intellectual disabilities or those who were discharged from secure wards. The review has implications for forthcoming psychiatric reforms in eastern Europe and elsewhere. It will help decision makers to tackle the argument that deinstitutionalisation will lead to homelessness and criminality among those with mental health problems, and it will also help stakeholders to justify reforms and advocate increased investment in mental health budgets.

\section{Future research}

The findings presented here suggest that Penrose's hydraulic hypothesis might need to be reconsidered. In Penrose's time de facto all public mental healthcare investment went into psychiatric hospitals. Decreasing the number of psychiatric beds signified decreasing investment in mental healthcare. This has, however, changed with the discovery of effective psychopharmaceuticals and with the introduction of new forms of care, both of which emerged roughly in the mid-20th century. Now, a decrease in the number of psychiatric beds no longer necessarily means a decreasing investment in mental healthcare. Instead, as a consequence of the increasing burden of mental disorders and more pressure on the availability of good-quality care in the community, investments into mental health might be rising, whereas the number of beds in mental hospitals might be simultaneously decreasing. Deinstitutionalisation has been criticised and its association with homelessness and criminality among those with mental disorders has been suggested mainly in locations where there have also been deep societal changes, mental health budget cuts and insufficient investment into the development of appropriate multilayered care in the community. Together, these factors suggest that Penrose's hydraulic hypothesis could be stated more precisely as the idea that criminality and homelessness increase as efficacious public investment into mental health decreases. Further research is needed to examine this refined hypothesis.

\footnotetext{
Petr Winkler, PhD, Department of Social Psychiatry, National Institute of Mental Health, Klecany, Czech Republic, and Health Service and Population Research Department, Institute of Psychiatry, King's College London, UK; Barbara Barrett Depart PhD, Paul Mccrone, PhD, Health Service and Population Research Department,
Institute of Psychiatry, King's College London, UK; Ladislav Csémy, PhD, Miroslava Institute of Psychiatry, King's College London, UK; Ladislav Csémy, PhD, Miroslava
Janoušková, PhD, Cyril Höschl, DSc, FRCPsych, Department of Social Psychiatry, National Institute of Mental Health, Klecany, Czech Republic

Correspondence: Dr Petr Winkler, Department of Social Psychiatry, National Institute of Mental Health, Topolová 748, 25067 Klecany, Czech Republic. Email: petr.winkler@nudz.cz

First received 10 Dec 2014, final revision 6 Jul 2015, accepted 12 Oct 2015
}

\section{Funding}

This work was supported by the Czech National Institute of Mental Health grant CZ.1.05/ 2.1.00/03.0078 and by the European Regional Development Fund. The funding source had no role in study design, data collection and analysis, interpretation of the results, writing the report or the decision to submit the paper for publication.

\section{Acknowledgements}

We acknowledge the excellent support from the King's College London library team.

\section{References}

1 Lamb HR, Weinberger LE. Persons with severe mental illness in jails and prisons: a review. Psychiatr Serv 1998; 49: 483-92.

2 Penrose LS. Mental disease and crime: outline of a comparative study of European statistics. Br J Med Psychol 1939; 18: 1-15.
3 Banks SM, Stone JL, Pandiani JA, Cox JF, Morschauser PC. Utilization of local jails and general hospitals by state psychiatric center patients. J Behav Health Serv Res 2000; 27: 454-9.

4 Swartz MS. Advancing research at the intersection of two systems. Psychiatr Serv 2010; 61: 431

5 Conacher GN. Psychiatric hospital downsizing and the Penrose effect. J Nerv Ment Dis 1996; 184: 708-10.

6 Susnick LC, Belcher JR. Why are they homeless? The chronically mentally ill in Washington, DC. Int J Mental Health 1996; 24: 70-84.

7 Lamb HR. Does deinstitutionalization cause criminalization? The Penrose hypothesis. JAMA Psychiatry 2015; 72: 105-6.

8 Mundt AP, Chow WS, Arduino M, Barrionuevo H, Fritsch R, Girala N, et al. Psychiatric hospital beds and prison populations in South America since 1990: does the Penrose hypothesis apply? JAMA Psychiatry 2015; 72: 112-8.

9 Lesage AD, Morissette R, Fortier L, Reinharz D, Contandriopoulos AP. Downsizing psychiatric hospitals: needs for care and services of current and discharged long-stay inpatients. Can J Psychiatry 2000; 45: 526-32.

10 Christenfeld R. Deinstitutionalization and its critics: a commentary on Brown. J Community Psychol 1982; 10: 176-80.

11 Davis L, Fulginiti A, Kriegel L, Brekke JS. Deinstitutionalization. Where have all the people gone? Curr Psychiatry Rep 2012; 14: 259-69.

12 Leff J, Dayson D, Gooch C, Thornicroft G, Wills W. Quality of life of long stay patients discharged from two psychiatric institutions. Psychiatr Serv 1996; 47: $62-7$

13 Sealy $P$, Whitehead PC. The impact of deinstitutionalization of psychiatric hospitals on psychological distress of the community in Canada. J Health Soc Policy 2006; 21: 73-94.

14 Herman NJ, Smith CM. Mental hospital depopulation in Canada: patient perspectives. Can J Psychiatry 1989; 34: 386-91.

15 Novella EJ. Mental Health care in the aftermath of deinstitutionalization: a retrospective and prospective view. Health Care Anal 2010; 18: 222-38.

16 Pijl YJ, Kluiter H, Wiersma D. Deinstitutionalisation in the Netherlands. Eur Arch Psychiatry Clin Neurosci 2001; 251: 124-9.

17 Munk-Jorgensen P. Has deinstitutionalization gone too far? Eur Arch Psychiatry Clin Neurosci 1999; 249: 136-43.

18 Novella EJ. Theoretical accounts on deinstitutionalization and the reform of mental health services: a critical review. Med Health Care Philos 2008; 11: 303-14.

19 Vazquez-Barquero JL, Garcia J, Torres-Gonzalez F. Spanish psychiatric reform: what can be learned from two decades of experience? Acta Psychiatr Scand 2001; 104: 89-95.

20 Priebe S, Badesconyi A, Fioritti A, Hansson L, Kilian RT, Torres-Gonzales F, et al. Reinstitutionalisation in mental-health care: comparison of data on service provision from six European countries. BMJ 2005; 330: 123-6.

21 Saraceno B. Methodological questions in Italian psychiatric reform. Riv Inferm 1989; 8: 52-60.

22 Haug HJ, Rossler W. Deinstitutionalization of psychiatric patients in central Europe. Eur Arch Psychiatry Clin Neurosci 1999; 249: 115-22.

23 Rosen A. The Australian experience of deinstitutionalization: interaction of Australian culture with the development and reform of its mental health services. Acta Psychiatr Scand 2006; 113: 81-9.

24 Young L, Ashman AF. Deinstitutionalisation in Australia. Part I: historical perspective. Br J Dev Disabil 2004; 50: 21-8.

25 Joseph $A E$, Kearns RA, Moon G. Recycling former psychiatric hospitals in New Zealand: echoes of deinstitutionalisation and restructuring. Health Place 2009; 15: 79-87.

26 Whitley R, Hickling FW. Open papers, open minds? Media representations of psychiatric de-institutionalization in Jamaica. Transcult Psychiatry 2007; 44: 659-71.

27 Hickling FW. Community psychiatry and deinstitutionalization in Jamaica. Hosp Community Psychiatry 1994; 45: 1122-6.

28 Semrau M, Barley EA, Law A, Thornicroft G. Lessons learned in developing community mental health care in Europe. World Psychiatry 2011; 10: 217-25.

29 Ito H, Setoya $Y$, Suzuki Y. Lessons learned in developing community mental health care in East and South East Asia. World Psychiatry 2012; 11: 186-90.

30 Appleby L, Desai PN. Documenting the relationship between homelessness and psychiatric hospitalization. Hosp Community Psychiatry 1985; 36: 732-7.

31 Gralnick A. Build a better state hospital: deinstitutionalization has failed. Hosp Community Psychiatry 1985; 36: 738-41.

32 Scott J. Homelessness and mental illness. Br J Psychiatry 1993; 162: 314-24.

33 Wallace $C$, Mullen PE, Burgess P. Criminal offending in schizophrenia over a 25 -year period marked by deinstitutionalization and increasing prevalence of comorbid substance use disorders. Am J Psychiatry 2004; 161: 716-27. 
34 Winerip M. Bedlam on the streets. The New York Times Magazine 1999; 23 May: 42-9, 56, 65-6.

35 Hodgins S, Muller-Isberner R, Allaire JF. Attempting to understand the increase in the numbers of forensic beds in Europe: a multi-site study of patients in forensic and general psychiatric services. Int J Forens Mental Health 2006; 5: 173-84.

36 Raphael S, Stoll MA. Assessing the contribution of the deinstitutionalization of the mentally ill to growth in the U.S. incarceration rate. J Legal Stud 2013; 42: $187-222$.

37 Kramp P, Gabrielsen G. The organization of the psychiatric service and criminality committed by the mentally ill. Eur Psychiatry 2009; 24: 401-11.

38 Hartvig P, Kjelsberg E. Penrose's Law revisited: the relationship between mental institution beds, prison population and crime rate. Nord J Psychiatry 2009; 63: 51-6.

39 Bassuk EL, Lamb HR. Homelessness and the implementation of deinstitutionalization. New Dir Ment Health Serv 1986; 30: 7-14.

40 Whitmer GE. From hospitals to jails: the fate of California's deinstitutionalized mentally ill. Am J Orthopsychiatry 1980; 50: 65-75.

41 Maj M. The rights of people with mental disorders: WPA perspective. Lancet 2011; 378: 1534-5.

42 World Health Organization. Mental Health Action Plan 2013-2020. WHO, 2013.

43 European Commission. Green Paper: Improving the Mental Health of the Population. Towards a Strategy on Mental Health for the European Union. EC, 2005

44 Prins SJ. Does transinstitutionalization explain the overrepresentation of people with serious mental illnesses in the criminal justice system? Community Ment Health J 2011; 47: 716-22.

45 David I. Vládní Reforma - Tentokrát Psychiatrie [Governmental reform psychiatry this time]; 2013 (http://www.prvnizpravy.cz/sloupky/vladnireforma-tentokrat-psychiatrie/).

46 Reforma Psychiatrie? Mù_e Vést k Masivnímu Bezdomovectví [Reform of psychiatry? It might lead to massive homelessness]; Lidovky.cz, 2013 (http:// relax.lidovky.cz/reforma-psychiatrie-pry-neni-vyvazena-z-pacientu-budoubezdomovci-1fi-/zdravi.aspx?c=A130311_161024_In-zdravi_pef).

47 Chystaná reforma psychiatrie je nevyvá_ená, z pacientù se stávají bezdomovci [Forthcoming psychiatric reform is unbalanced, patients are getting homeless]. Deník, 2013 (http://www.denik.cz/z_domova/chystanareforma-psychiatrie-je-nevyvazena-z-pacientu-se-stavaji-bezdomovci-2013. html).

48 Reforma psychiatrie udilá z pacientù bezdomovce, varuji kritici [Reform of psychiatry will drive patients into homelessness, critics warn]; ÈT24, 2013 (http://www.ceskatelevize.cz/ct24/domaci/218377-reforma-psychiatrieudela-z-pacientu-bezdomovce-varuji-kritici/).

49 Ruení léèeben pole nemocné na ulici, varuje studie [Closing of mental hospitals will send patients into streets, study warns]; Czech News Agency, 2013 (http://zpravy.aktualne.cz/domaci/ruseni-leceben-posle-nemocnena-ulici-varuje-studie/r i:article:773657/).

50 Leff J. Care in the Community: Illusion or Reality? Wiley, 1997.

51 Francis VM, Vesey P, Lowe G. The closure of a long-stay psychiatric hospital: a longitudinal study of patients' behavior. Soc Psychiatry Psychiatr Epidemio 1994; 29: 184-9.

52 McInerney SJ, Finnerty S, Avalos G, Walsh E. Better off in the community? A 5-year follow up study of long-term psychiatric patients discharged into the community. Soc Psychiatry Psychiatr Epidemiol 2010; 45: 469-73.

53 Jones $K$, Robinson $M$, Golightley $M$. Long-term psychiatric patients in the community. Br J Psychiatry 1986; 149: 537-40.

54 Kunitoh N. From hospital to the community: the influence of deinstitutionalization on discharged long-stay psychiatric patients. Psychiatry Clin Neurosci 2013; 67: 384-96.

55 Livingston MG, Bryson A. The Glasgow rehabilitation survey. Br J Psychiatry 1989; 154: 620-4.

56 Gottheil E, Winkelmayer R, Smoyer $\mathrm{P}$, Exline R. Characteristics of patients who are resistant to deinstitutionalization. Hosp Community Psychiatry 1991 42: 745-8.

57 Barr R, Parker G. Effects of discharge on long-stay psychiatric hospital patients. Aust NZ J Psychiatry 1975; 9: 47-9.

58 Carta MG, Agaj A, Harapej E, Lecca ME, Xhelili G, Altoe G, et al. Outcomes of discharged females versus those waiting for discharge from Vlore Psychiatric Hospital (Albania). Int J Soc Psychiatry 2013; 59: 682-9.

59 Chan $\mathrm{H}$, Inoue S, Shimodera S, Fujita H, Fukuzawa K, Kii M, et al. Residential program for long-term hospitalized persons with mental illness in Japan: randomized controlled trial. Psychiatry Clin Neurosci 2007; 61: 515-21.
60 Honkonen T, Saarinen S, Salokangas RKR. Deinstitutionalization and schizophrenia in Finland: II. Discharged patients and their psychosocial functioning. Schizophr Bull 1999; 25: 543-51.

61 Haberfellner EM, Grausgruber A, Grausgruber-Berner R, Ortmair M, Schony W. Deinstitutionalization of long-stay psychiatric patients in upper Austria living situation, social and clinical characteristics more than one year after discharge. Psychiatr Prax 2004; 31: 192-7.

62 Mizuno M, Sakuma K, Ryu Y, Munakata S, Takebayashi T, Murakami M, et al. The Sasagawa Project: a model for deinstitutionalisation in Japan. Keio J Med 2005; 54: 95-101.

63 Okin RL, Borus JF, Baer L, Jones A. Long-term outcome of state hospital patients discharged into structured community residential settings. Psychiatr Serv 1995; 46: 73-8.

64 Thornicroft G, Bebbington P, Leff J. Outcomes for long-term patients one year after discharge from a psychiatric hospital. Psychiatr Serv 2005; 56: 1416-22.

65 McGrew JH, Wright ER, Pescosolido BA, McDonel EC. The closing of Central State Hospital: long-term outcomes for persons with severe mental illness. J Behav Health Serv Res 1999; 26: 246-61.

66 Hobbs C, Newton L, Tennant C, Rosen A, Tribe K. Deinstitutionalization for long-term mental illness: a 6-year evaluation. Aust NZ J Psychiatry 2002; 36 60-6.

67 Furlan PM, Zuffranieri M, Stanga F, Ostacoli L, Patta J, Picci RL. Four-year follow-up of long-stay patients settled in the community after closure of Italy's psychiatric hospitals. Psychiatr Serv 2009; 60: 1198-202.

68 Donnelly M, McGilloway S, Mays N, Knapp M, Kavanagh S, Beecham J, et al. One and two year outcomes for adults with learning disabilities discharged to the community. Br J Psychiatry 1996; 168: 598-606.

69 Farragher B, Carey T, Owens J. Long term follow-up of rehabilitated patients with chronic psychiatric illness in Ireland. Psychiatr Serv 1996; 47: 1120-2.

70 MacGilp D. A quality of life study of discharged long-term psychiatric patients. J Adv Nurs 1991; 16: 1206-15.

71 Barbato A, D'Avanzo B, Rocca G, Amatulli A, Lampugnani D. A study of longstay patients resettled in the community after closure of a psychiatric hospital in Italy. Psychiatr Serv 2004; 55: 67-70.

72 Mastroeni A, Bellotti C, Pellegrini E, Galletti F, Lai E, Falloon IRH. Clinical and social outcomes five years after closing a mental hospital: a trial of cognitive behavioural interventions. Clin Pract Epidemiol Ment Health 2005; 1: 25.

73 Rothbard $A B$, Kuno E, Schinnar AP, Hadley TR, Turk R. Service utilization and cost of community care for discharged state hospital patients: a 3-year follow-up study. Am J Psychiatry 1999; 156: 920-7.

74 Donnelly M, McGilloway S, Mays N, Perry S, Lavery C. A three- to six-year follow-up of former long-stay residents of mental handicap hospitals in Northern Ireland. Br J Clin Psychol 1997; 36: 585-600.

75 Farragher B, Carey T, Owens J. Long-term follow-up of rehabilitated patients with chronic psychiatric illness in Ireland. Psychiatr Serv 1996; 47: 1120-2.

76 Andrews G, Teesson M, Stewart G, Hoult J. Follow-up of community placement of the chronic mentally ill in New South Wales. Hosp Community Psychiatry 1990; 41: 184-8.

77 Armstrong B. A federal study of deinstitutionalization: how the government impedes its goal. Hosp Community Psychiatry 1977; 28: 421-25.

78 Langsley DG, Barter JT, Yarvis RM. Deinstitutionalization: the Sacramento story. Compr Psychiatry 1978; 19: 479-90.

79 Leeman CP. The 'least restrictive environment': from rhetoric to practice. Gen Hosp Psychiatry 1980; 2: 229-32.

80 Okin RL. Testing the limits of deinstitutionalization. Psychiatr Serv 1995; 46 : 569-74.

81 Ozarin LD, Sharfstein SS. The aftermaths of deinstitutionalization: problems and solutions. Psychiatr Q 1978; 50: 128-32.

82 Pilisuk M. A job and a home: social networks and the integration of the mentally disabled in the community. Am J Orthopsychiatry 2001; 71: 49-60.

83 Searight HR, Handal PJ. The paradox of psychiatric deinstitutionalization: historical perspective and policy implications. J Health Hum Resour Adm 1988; 11: 249-66.

84 Talbott JA. Presidential address: our patients' future in a changing world: the imperative for psychiatric involvement in public policy. Am J Psychiatry 1985; 142: 1003-14.

85 Talbott JA. Deinstitutionalization: avoiding the disasters of the past. Hosp Community Psychiatry 1979; 30: 621-4.

86 Wachholz S, Mullaly R. Policing the deinstitutionalized mentally-ill - toward an understanding of its function. Crime Law Soc Change 1993; 19: 281-300.

87 Hope M, Young J. From back wards to back alleys - deinstitutionalization and the homeless. Urban Soc Change Rev 1984; 17: 7-11.

88 Durham ML. The impact of deinstitutionalization on the current treatment of the mentally-ill. Int J Law Psychiatry 1989; 12: 117-31. 
89 Dumont MP, Dumont DM. Deinstitutionalization in the United States and Italy: a historical survey. Int J Ment Health 2008; 37: 61-7.

90 Knowles C. Burger King, Dunkin Donuts and community mental health care. Health Place 2000; 6: 213-24.

91 Caldas de Almeida JM, Horvitz-Lennon M. Mental health care reforms in Latin America: an overview of mental health care reforms in Latin America and the Caribbean. Psychiatr Serv 2010; 61: 218-21.

92 Dickey B, Gudeman JE, Hellman S, Donatelle A, Grinspoon L. A follow-up of deinstitutionalized chronic patients four years after discharge. Hosp Community Psychiatry 1981; 32: 326-30.

93 Rothbard $A B$, Kuno $E$. The success of deinstitutionalization. Empirical findings from case studies on state hospital closures. Int J Law Psychiatry 2000; 23 329-44

94 Gardos G, Cole JO, LaBrie RA. A 12-year follow-up study of chronic schizophrenics. Hosp Community Psychiatry 1982; 33: 983-4.

95 Double $\mathrm{D}$, Wong $\mathrm{T}$. What has happened to patients from long-stay psychiatric wards? Psychiatr Bull 1991; 15: 735-6.

96 Nordentoft M, Ohlenschlaeger J, Thorup A, Petersen L, Jeppesen P, Bertelsen M. Deinstitutionalization revisited: a 5-year follow-up of a randomized clinical trial of hospital-based rehabilitation versus specialized assertive intervention (OPUS) versus standard treatment for patients with firstepisode schizophrenia spectrum disorders. Psychol Med 2010; 40: 1619-26.

97 Wahlbeck K, Westman J, Nordentoft M, Gissler M, Laursen TM. Outcomes of Nordic mental health systems: life expectancy of patients with mental disorders. Br J Psychiatry 199: 453-8.

98 Coldwell CM, Bender WS. The effectiveness of assertive community treatment for homeless populations with severe mental illness: a metaanalysis. Am J Psychiatry 2007; 164: 393-9.

99 Kertesz SG, Weiner SJ. Housing the chronically homeless: high hopes, complex realities. JAMA 2009; 301: 1822-4.

100 Somers JM, Rezansoff SN, Moniruzzaman A, Palepu A, Petterson M. Housing first reduces re-offending among formerly homeless adults with mental disorders: results of a randomized controlled trial. PLOS One 2013; 8: e72946.

101 United Nations General Assembly. Convention on the Rights of Persons with Disabilities: Resolution. UN General Assembly, 2007 (http://www. refworld.org/docid/45f973632.html).

\title{
The Anatomy of Melancholy by Robert Burton
}

\author{
German E. Berrios
}

The Anatomy of Melancholy (1621) continues featuring in all histories of 'depression' and/or 'melancholy' (as per the current meaning given to these terms). This erroneous inclusion may be due to anachronistic reading, lazy repetition of earlier claims or mere ignorance. Be that as it may, over the years the false friends ('anatomy' and 'melancholy') have set a deserved trap to those who believe that this book offers an 'early insight into the neural networks (anatomy) that underlie depressive illness (melancholy)'.

The fact that by the end of the 16th century the old Greek word 'anatomy' was already being used figuratively (e.g. anatomy of mischief, anatomy of grief) explains Robert Burton's (1577-1640) choice. In turn, the polysemic term 'melancholy' carried, in addition to its classical Hippocratic reference to malaria and black bile, an allusion to 'love-melancholy' - as Lawrence Babb identified in Elizabethan poetry. If to these linguistic usages the fact is added that by the early 1600 s centoising had become fashionable as a show of erudition, then it makes sense to see The Anatomy of Melancholy for what it is, an anthology of classical quotations referring to human emotions, passions, feelings, dissatisfactions and complaints about life. The fact that the quotation-hunter can find in this book support for any claim they may wish to make explains the persistent presence of Burton's cento in histories of depression, hypochondria, anxiety, obsessive-compulsive behaviour, and so on.

If The Anatomy of Melancholy is not really about psychiatry, then, what is it about? The greatest among Burton's scholars, John Bamborough (1921-2009), described it as an omnium gatherum, a literary genre according to which only successful centos, i.e. those truly encompassing the knowledge of a historical period, could contain hidden 'truths'. In this epistemological sense, during the early 17th century Burton's book played a social, political and scientific role comparable to that of meta-analysis in our own day.

To write his book Burton ransacked about 1500 classical texts. It ended up being half a million words' long (including 8000 footnotes). The five 'revisions' that followed caused it to have a multi-layered structure and Burton's original intention of writing a consolatory (partially self-therapeutic) religious discourse was well-nigh lost under a frondous canopy of 'medical' quotations. Influences shaping the book ranged from Archipathologia (1614), the great cento written by P. E. Montalto (1557-1616), to ongoing innovations in map-making and in the concept of geography. The thread stitching the patchwork of Burton's work together was no doubt his balanced scholarship, literary sensitivity and his readiness to take personal responsibility for all he had stated in his book. In contrast to the great centos of the past, meta-analysis explores a 'knowledge' base that presents itself as impersonal, universal and immanently 'truth-making'

Reams have been written on The Anatomy of Melancholy. Those who really want to know it should approach it with different eyes and expectations and stop searching in it for descriptions redolent of 'bipolar disorder' or 'agoraphobia' or whatever. Given that all its content is borrowed from classical texts, seeing it as a 'psychiatric textbook' leads to the strange conclusion that all classical literature must also be regarded as psychiatric in nature! The Anatomy of Melancholy must be seen as a cultural object whose meaning, as time goes by, is becoming increasingly harder to apprehend. It teaches us something far more important than psychiatry: it provides us with the epistemological coordinates with which we can understand the remote world of the 17th century. 